\title{
Comparison of Led Fluorescent Microscopy and the Gene Xpert MTB/ RIF Assay in Diagnosis of Pulmonary and Extrapulmonary Tuberculosis
}

\author{
Sanam Thapa Magar ${ }^{1}$, Pradeep Kumar Shah ${ }^{1 *}$ \\ ${ }^{1}$ Department of Microbiology, Tri-Chandra Multiple Campus, Ghantaghar, Kathmandu
}

*Corresponding author: Pradeep Kumar Shah, Associate Professor, Department of Microbiology, Tri-Chandra Multiple Campus, Ghantaghar, Kathmandu; Email: pkshah210@gmail.com

\section{ABSTRACT}

Objectives: The objective of this study was to evaluate Gene Xpert MTB/RIF Assay and anid fast staining (AFB) for rapid detection of Mycobacterium tuberculosis in specimen of patients suspected of pulmonary tuberculosis (PTB) and extra pulmonary tuberculosis (EPTB).

Methods: A comparative cross-sectional study of 400 samples (PTB-365 and EPTB-35) of patients visiting National Tuberculosis Centre (NTC) was conducted from July 2018 to December 2018. Gene Xpert MTB/ RIF Assay, smear microscopy were performed under standard guideline inside biosafety cabinet class II. The result obtained from both the tests were analyzed using SPSS 20.0 software and Excel 2019.

Results: Of the total samples, 18\% (72/400) and 39\% (156/400) were positive by AFB smear microscopy and Xpert MTB/RIF assay respectively. Prevalence of MTB positive was highest in the age group 35-44 years, 33cases (17.74\%) were detected in total, with a male to female ratio of 2.3:1. Pleural fluid, pus, and CSF fluid also yielded positive results with the Gene Xpert MTB/RIF assay accounting $1.28 \%, 0.64 \%$ and $1.28 \%$ of MTB positive case respectively. Rifampicin resistance was observed in $1.28 \%$ of the cases.

Conclusion: The key findings of this study suggest that Gene Xpert test should be implemented as primary diagnostic test for PTB and EPTB.

Key words: Gene Xpert MTB/RIF Assay, Mycobacterium tuberculosis, Pulmonary tuberculosis.

\section{INTRODUCTION}

Tuberculosis (TB) is considered one of the most important infectious diseases through the course of human history which can affect nearly any organ in the body, but it mostly causes lung infections (Azadi et al. 2018). Tuberculosis is a communicable disease resulting from infection with Mycobacterium tuberculosis whose principal reservoir is man and also, but infrequently, with other mycobacterium belonging to the Mycobacterium tuberculosis complex (Ayieko 2015).

According to the Global TB Report 2017, tuberculosis mortality rate was 23 per 100,000 populations, which includes both HIV positive and HIV negative people. It causes ill-health in millions of people each year and in 2015 was one of the top 10 causes of death worldwide, ranking above HIV/AIDS as one of the leading causes of death from an infectious disease. As per Global TB report 2017, 6000 to 7000 people were dying per year from TB disease in Nepal. NTP registered 31764 all forms of TB cases, which includes 30,957 incident TB cases (new and relapse) (NTP 2072/73 (2016). Most cases were reported in the productive age group (highest of $50 \%$ in 15-44 year of age). The proportion of new cases with multidrug-resistant TB (MDR-TB) was $2.2 \%$ among new cases and $15.4 \%$ among retreatment cases based on DRS survey carried out in 2011/12 (NTP 2018). The majority of TB cases and deaths occur among men, the burden of disease among women seems significantly lower (2:1) (WHO 2015).

The standard WHO recommendation for TB diagnosis in the DOTS program is the use of direct sputum
Date of Submission: November 5, 2019

Published Online: December, 2019
Date of Acceptance: December 3, 2019

DOI: https:/ / doi.org/10.3126/tujm.v6i0.26596 
microscopy on 3 stained sputum specimens Sputum microscopy, the most widely available test for active TB (Matee et al. 2008). Although smear microscopy for acid-fast bacilli (AFB) is rapid and inexpensive, it has poor sensitivity and a poor positive predictive value (PPV). In HIV infected patients with pulmonary TB, 24-61\% have acid-fast negative sputum smear (Pinyopornpanish et al. 2015). Mycobacterial culture is the gold standard and the most sensitive method for TB diagnosis; however, the use in clinical practice is limited due to a slow turnaround time ( 2 to 8 weeks), biosafety requirements, and high cost. Several studies have demonstrated that Xpert assay is highly sensitive and specific in diagnosis of both pulmonary and extrapulmonary TB (Pinyopornpanish et al. 2015). Thus, rapid identification, which is essential for earlier treatment initiation, improved patient outcomes, and more effective public health interventions, relies on nucleic acid amplification techniques. The GeneXpert MTB/RIF assay is a novel integrated diagnostic device that performs sample processing and heminested real-time PCR analysis in a single hands-free step for the diagnosis of tuberculosis and rapid detection of RIF resistance in clinical specimens (Zeka et al. 2011). The assay has been endorsed by the World Health Organization (WHO) since 2010 and its 2015 policy statement recommends that the Xpert®MTB/RIF should be available to all who need it and prioritized for persons at risk of multidrug-resistant TB (MDRTB) and HIV- associated TB. Very importantly, in the same policy statement WHO emphasizes that DST for anti-TB medicines other than rifampicin should also be offered (Zaragoza and Laborin 2017). The MTB/ RIF assay detects $M$. tuberculosis and RIF-resistance by PCR amplification of the 81-bp fragment of the $M$. tuberculosis rpoB gene and subsequent probing of this region for mutations that are associated with RIFresistance. The assay can generally be completed in less than $2 \mathrm{hr}$ (Zeka et al. 2011). It is technically simple to conduct and is safe as it produces no culturable aerosols (Bajrami et al. 2018).

The currently recommended treatment for new cases of drug-susceptible TB is a six-month regimen (fixed dose combination) of four first-line drugs: isoniazid, rifampicin, Ethambutol and pyrazinamide. Cured rates was $84 \%$ and Treatment Success Rates was $91 \%$ for new cases reported in 2016/17. The lack of availability and access to an early screening of presumptive TB cases with rapid DST may still be the main reasons for this stagnation of DR-TB cases (NTP 2018). Therefore, this study has significant importance in rapid diagnosis of tuberculosis of patients suspected of Pulmonary and Extra Pulmonary tuberculosis. Additional to diagnosis, this study has importance in direct detection of RIFresistance which therefore, can provide the basis for prompt treatment of DR tuberculosis. Therefore, this study about rapid and effective diagnosis of pulmonary tuberculosis may evolve insight on use of Gene Xpert MTB/RIF assay throughout the country in achieving the target of treating all the infected patients of tuberculosis and therefore might helps in curbing rapturous distribution of tuberculosis.

\section{MATERIALS AND METHODS}

This hospital based cross-sectional study was carried out in National Tuberculosis center, Thimi, Bhaktapur, in collaboration with Department of Microbiology, TriChandra Multiple Campus, Ghantaghar, Kathmandu, Nepal from July, 2018 to December 2018. A total of 400 different specimens from patients suspected of tuberculosis (pulmonary and extra pulmonary) were taken. The inclusion criteria were male or female patients with age $\geq 15 \mathrm{yrs}$, clinically suspected patients with characteristics symptoms and with or without abnormal chest radiography. While inappropriately labeled and collected specimens (sputum containing saliva only, food particles or other solid particulates) and Patients with previous history of receiving antituberculous drug within 3 months before enrollment were excluded.

For this study, they were requested for two consecutive sputum from 357 PTB suspects i.e. first day for Gene Xpert MTB/RIF Assay, considered as sample II and second day for LED fluorescent microscopy, considered as sample I (spot sample). Then the same specimenII was processed for LED fluorescent microscopy and for Xpert MTB/RIF test. While a single specimen each from 35-EPTB suspects and 8-BAL (PTB suspects) were collected as per the collection and transportation policy of the laboratory and proceeded for AFB microscopy. Patients were instructed on the difference between sputum, saliva or nasopharyngeal secretions and the necessity for a deep, productive cough. And EPTB suspected body specimens (Pus, CSF fluid, Ascitic fluid, Pleural fluid and BAL) were brought by the patients in a container supplied by any other hospitals where they took service at. 
Direct smear microscopy was performed to investigate presence of AFB with the sample-II using Fluorochrome staining technique. And the AFB results were reported using the criteria of $\mathrm{WHO} /$ International Union of Tuberculosis and Lung Diseases (IUTALD).

Gene Xpert testing was performed according to the manufacturer's instructions. Sample reagent was added to untreated specimen at a ratio of 2:1, vortexed thoroughly until clear solution was seen and it was left incubated at room temperature for $15 \mathrm{~min}$ on upright position. Between 5 and 10 minutes of incubation, the specimen was shaken vigorously again $10-20$ times. The tube was again incubated at RT for another $5 \mathrm{~min} .2 \mathrm{ml}$ of the liquefied and liquefied material was transferred to the test cartridge and inserted into the platform. The result interpretation was made by the GeneXpert DX System from measured fluorescent signals and embedded calculation algorithms and was displayed in the "View Results" window of the GeneXpert machine. The test was repeated using a new cartridge or initiated alternate procedures if test results exhibit error and invalid.

The data were collected, structured and analysis was done using SPSS version 20.0 System. Statistical analysis (i.e. Chi-Square) was employed on determining the association between fluorescent microscopy and Gene Xpert MTB/RIF Assay at 95\% confidence interval. A p-value less than 0.05 was considered statistically significant.

\section{RESULTS}

A total of 400 specimens from TB suspected subjects were recruited in the study of which $283(70.75 \%)$ were male and $117(29.25 \%)$ were female with a male to female ratio of 2.42:1. Most of the subjects 98 (28.50\%) were in the age 65 yrs and above (Table 1).

Table 1: Gender and age-wise distribution of patients

\begin{tabular}{|c|c|c|c|}
\hline \multicolumn{2}{|c|}{ Characteristics } & \multirow{2}{*}{$\begin{array}{c}\mathrm{N}=400 \\
117\end{array}$} & \multirow{2}{*}{$\begin{array}{c}\% \\
29.25\end{array}$} \\
\hline Condor & Female & & \\
\hline Gender & Male & 283 & 70.75 \\
\hline \multirow{6}{*}{ Age range (years) } & $15-24$ & 34 & 8.50 \\
\hline & $25-34$ & 40 & 10 \\
\hline & $35-44$ & 71 & 17.75 \\
\hline & $45-54$ & 73 & 18.25 \\
\hline & $55-64$ & 84 & 21 \\
\hline & $65+$ & 98 & 24.50 \\
\hline
\end{tabular}

Highest proportion was covered by pulmonary specimen (365) consists of $357(89.25 \%)$ sputum and $8(2 \%)$ BAL. 35 specimens were categorized as extrapulmonary that includes Pus-9, CSF-8, Pleural fluid-12 and Ascitic fluid-6. A total of 400 (365 pulmonary and 35 extra pulmonary) specimen were stained using LED Fluorescent staining technique. Of them $72(18 \%)$ were AFB positive and 328 (82\%) were AFB negative. Gene-Xpert positivity for MTB remained 156(39\%) (Table 2).

Table 2: Result of specimen on AFB smear and Gene-Xpert MTB/RIF assay

\begin{tabular}{ccccc}
\hline & & $\mathrm{N}=400$ & $\%$ \\
\hline \multirow{3}{*}{ Characteristics } & Sputum & 357 & 89.25 \\
& BAL & 8 & 2 & 2.25 \\
& Pus & 9 & 2 & 3 \\
& CSF & 8 & 1.5 & 0.25 \\
& Pleural fluid & 12 & 2 & 7 \\
& Ascitic fluid & 6 & 1 & 8.75 \\
\hline
\end{tabular}




\begin{tabular}{cccc}
\hline Characteristics & & $\mathrm{N}=400$ & $\%$ \\
\hline & $\mathrm{VL}$ & 25 & 6.25 \\
Gene-Xpert assay & $\mathrm{L}$ & 37 & 9.25 \\
& $\mathrm{M}$ & 68 & 17 \\
& $\mathrm{H}$ & 26 & 6.5 \\
& $\mathrm{~N}$ & 244 & 61 \\
\hline
\end{tabular}

Note: VL: Very low, L: Low, M: Medium. H: High and N: Negative

Eighty-four AFB negative samples gave MTB detected

Gene-Xpert MTB/RIF assay result and one MTB not-

detected case gave AFB positive result (Table 3).

Table 3: Distribution and findings on AFB smear and Gene-Xpert assay

\begin{tabular}{|c|c|c|c|c|c|c|}
\hline \multirow{2}{*}{ AFB smear result } & \multicolumn{5}{|c|}{ Gen-Xpert test } & \multirow{2}{*}{ Total } \\
\hline & VL & $\mathrm{L}$ & $M$ & $\mathrm{H}$ & $\mathrm{N}$ & \\
\hline Scanty & - & 1 & - & - & - & 1 \\
\hline $1+$ & - & 1 & 6 & - & 1 & 8 \\
\hline $2+$ & - & 2 & 5 & 21 & - & 28 \\
\hline $3+$ & & - & 16 & 19 & - & 35 \\
\hline Negative & 41 & 32 & 9 & 3 & 243 & 328 \\
\hline Total & 25 & 37 & 68 & 26 & 244 & 400 \\
\hline
\end{tabular}

Note: VL: Very low, L: Low, M: Medium. H: High and N: Negative

104 males and 45 females (149; $95.51 \%$ ) were sensitive and 2 males counting $100 \%$ were resistant to rifampicin among 156 MTB detected cases by Gene Xpert MTB/ RIF assay (Table 4).

Table 4: Gene Xpert MTB/RIF assay rifampicin sensitivity results

\begin{tabular}{|c|c|c|c|}
\hline \multirow{2}{*}{ Rifampicin sensitivity } & \multicolumn{2}{|c|}{ Gender } & \multirow[t]{2}{*}{ Total } \\
\hline & Male & Female & \\
\hline Sensitive & $104(69.8 \%)$ & $45(30.2 \%)$ & 149 \\
\hline Resistance & $2(100 \%)$ & - & 2 \\
\hline Indeterminate & $4(80 \%)$ & $1(20 \%)$ & 5 \\
\hline Total & 110 & 46 & 156 \\
\hline
\end{tabular}

\section{DISCUSSION}

Although AFB smear positive patients are considered highly infectious and being focused by most of clinicians, smear negative patients are also reported to responsible for approximately $17 \%$ of transmission and its impact on public health could not be neglected (Behr et al. 1999). Early diagnosis of TB is necessary to disrupt the disease transmission chain.

In this study, smear positivity was found to be $72(18 \%)$ and Gene-Xpert positivity for MTB remained 156 (39\%), are not in agreement with a study, which showed higher smear positivity of $67.5 \%$ by Auramine fluorochrome staining and MTB positivity of $77.4 \%$ by Gene-Xpert (Munir et al. 2015). This variation may be explained by differences in physiological and medical conditions of the subjects, or inclusion of highly suspicious subjects.
On age wise distribution, 33(21.15\%) out of 71 (male positive; $14.74 \%$ \& female positive; $6.41 \%$ ) being highest number of patients in age group 35-44 were diagnosed MTB positive respectively. The result suggests that TB infection case is most likely common among the economically active group that directly impacts to the family and the national economy (Bhatt 2009).

In this study, among 156 Gene Xpert Positive isolates, RIF resistance was detected in 2 male cases (1.28\%), RIF sensitive in 104 male cases (66.67\%) and 45 (28.85\%) female cases. A wide range of $0-6.1 \%$ resistance for MTB positivity by Gene Xpert has been reported in earlier studies (Green et al. 2010 (6.1\%); Khunjeli et al. 2014 (4.8\%); Atashi et al. 2017 (3.1\%); Pradhan et al. 2014 (4.2\%). Low frequency of RIF-resistance TB in our study may be due to the exclusion criteria i.e excluding 
retreatment cases or failure cases in our study design. The reasons for the marked resistance rate might be due to delay in treatment and unavailability of drugs among the subjects under study.

Sixty-nine (19.33\%) spot sputum samples (sample I) and $72(20.17 \%)$ morning samples (sample II) were smear positive (LED FM). In high-burden settings, the elimination of the third specimen and the resultant reduction in workload may actually improve case detection by improving the quality of examination of the first two specimens (Islam 2013).

Ironically, areas of high prevalence such as Nepal, the majority of suspected TB cases are assessed by sputum smear microscopy and, where available, by tuberculin test, ESR, ADA, CXR. Patients are often placed to pragmatic empirical treatment practices on the basis of symptomatic analysis or abnormal CXR alone (Shrestha et al. 2015). In these perspectives, Gene Xpert excludes "false cases" to "true" smear-negative TB cases, with enhanced accuracy of treatment, cost-effectiveness reducing the burden of toxicity and opportunity cost of treatment in patients suspected TB (Shrestha et al. 2015; Steingart et al. 2006; Dowdy et al. 2011).

Positive predictive value and Negative predictive value of Gene Xpert MTB/ RIF Assay with reference to culture in the diagnosis of PTB was $76.74 \%, 95.79 \%$, $89.19 \%$ and $90.09 \%$ respectively (Thapa et al. 2016). With regard to this study, use of Gene Xpert MTB/ RIF assay could significantly reduce false negative AFB staining results and the delay in treatment initiation, reducing premature death and transmission. Rapid detection of RIF resistance is considered crucial for the control of MDR-TB.

\section{CONCLUSION}

This study reveals, an appliance of Xpert MTB/RIF assay as a diagnostic tool improved the additional case detection of smear negative Pulmonary and Extra pulmonary tuberculosis that often missed with smear microscopy. Therefore, implementation of molecular approaches for direct diagnosis of MDR TB, as a part of routine analysis in the laboratories of health care institutions, would be of great benefit in adapting treatment regimens, limiting dissemination of MDR TB strains.

\section{ACKNOWLEDGEMENTS}

We are very grateful to Gokarna Raj Ghimire, NTC, Thimi, Bhaktapur and Tri-Chandra Multiple Campus,
Ghantaghar, Kathmandu, staff of both campus and hospital and as well as patients for their support and compliance during the study period.

\section{CONFLICT OF INTEREST}

The authors declare no conflict of interest.

\section{REFERENCES}

Atashi S, Izadi B, Jalilian S, Madani SH, Farahani A and Mohajeri P (2017). Evaluation of GeneXpert MTB/RIF for determination of rifampicin resistance among new tuberculosis cases in west and northwest Iran. New Microbes and New Infections 19: 117-20.

Ayieko YS (2015). Epidemiology of tuberculosis and human immunodeficiency virus coinfection, clinical presentations and impact on immunohaematological parameters in Mombasa county, Kenya (Doctoral dissertation, Kenyatta).

Azadi D, Motallebirad T, Ghaffari K and Shojaei H (2018). Mycobacteriosis and Tuberculosis: Laboratory Diagnosis. The Open Microbiology Journal 12: 41.

Bajrami R, Mulliqi G, Kurti A, Lila G and Raka L (2018). Assessment of diagnostic accuracy of GeneXpert Mycobacterium tuberculosis/rifampicin in diagnosis of pulmonary tuberculosis in Kosovo. Biomedical and Biotechnology Research Journal (BBRJ) 2(3): 191.

Bhatt CP, Bhatt AB and Shrestha B (2009). Nepalese People's knowledge about Tuberculosis. SAARC Journal of Tuberculosis, Lung Diseases and HIV/ AIDS 6(2):31-7.

Dowdy DW, Cattamanchi A, Steingart KR and Pai M (2011). Is Scale-Up Worth It? Challenges in Economic Analysis of Diagnostic Tests for Tuberculosis. PLoS Med 8(7): e1001063.

Green E, Obi CL, Nchabeleng M, De Villiers BE, Sein PP, Letsoalo T, Hoosen AA, Bessong PO and Ndip RN (2010). Drug-susceptibility patterns of Mycobacterium tuberculosis in Mpumalanga province, South Africa: possible guiding design of retreatment regimen. Journal of Health, Population, and Nutrition 28(1): 7.

Islam MR, Khatun R, Uddin MK, Khan MS, Rahman MT, Ahmed T and Banu S (2013). Yield of two consecutive sputum specimens for the effective 
diagnosis of pulmonary tuberculosis. PLoS One 8(7): e67678.

Khunjeli R, Mohsin UR, Shrestha SK, Adhikari S, Srivastava B and Shrestha B (2014). Prevalence of Primary Drug Resistant Tuberculosis in a Tertiary Care Hospital, Nepal. J Chitwan Med Coll 4(10): 36-38.

Matee M, Mtei L, Lounasvaara T, Wieland-Alter W, Waddell R, Lyimo J, Bakari M, Pallangyo K and Von Reyn CF (2008). Sputum microscopy for the diagnosis of HIV-associated pulmonary tuberculosis in Tanzania. BMC Public Health 8(1): 68.

Munir MK, Rehman S, Aasim M, Iqbal R and Saeed S (2015). Comparison of Ziehl Neelsen microscopy with GeneXpert for detection of Mycobacterium tuberculosis. IOSR Journal of Dental and Medical Sciences 14(11): 56-60.

NTP (2072/73 (2016)). Annual report. Government of Nepal Ministry of Health and Population, Department of Health services, Thimi, Bhaktapur.

NTP Nepal. (2018). NTP Nepal Annual Report. Ministry of Health \& Population, Nepal, Department of Health Services. National Tuberculosis Center.

Pinyopornpanish K, Chaiwarith R, Pantip C, Keawvichit R, Wongworapat K, Khamnoi P, Supparatpinyo K and Sirisanthana T (2015). Comparison of Xpert MTB/RIF assay and the conventional sputum microscopy in detecting Mycobacterium tuberculosis in Northern Thailand. Tuberc Res Treat 2015: 571782.
Pradhan P, Poudyal N, Gurung R, Acharya A and Bhattacharya SK (2014). Drug resistance pattern of Mycobacteria isolated from smear positive cases of pulmonary tuberculosis in eastern part of Nepal. JGPEMN 3(4): 7-12.

Shrestha P, Arjyal A, Caws M, Prajapati KG, Karkey A, Dongol S, Pathak S, Prajapati S and Basnyat B (2015). The application of GeneXpert MTB/ RIF for smear-negative TB diagnosis as a fee paying service at a South Asian General Hospital. Tuberc Res Treat 2015:102430.

Thapa G, Pant ND, Khatiwada S and Shrestha B (2016). Drug susceptibility patterns of the Mycobacterium tuberculosis isolated from previously treated and new cases of pulmonary tuberculosis at German-Nepal tuberculosis project laboratory, Kathmandu, Nepal. Antimicrobial Resistance $\mathcal{E}$ Infection Control 5(1): 30.

World Health Organization (2018). Global tuberculosis report 2018. Geneva, Switzerland: World Health Organization ISBN 978-92-4-156564-6

Zaragoza B and Laniado-Laborín R (2017). Diagnosing Drug-Resistant Tuberculosis with the Xpert ${ }^{\circledR}$ MTB/RIF. The Risk for Rifampin Susceptible Cases. Journal of Tuberculosis Research 5(03): 155.

Zeka AN, Tasbakan S and Cavusoglu C (2011). Evaluation of the GeneXpert MTB/RIF assay for rapid diagnosis of tuberculosis and detection of rifampin resistance in pulmonary and extrapulmonary specimens. Journal of Clinical Microbiology 49(12): 4138-4141. 